\title{
Rehabilitative treatment of cleft lip and palate: experience of the Hospital for Rehabilitation of Craniofacial Anomalies/USP (HRAC/USP) - Part 1: overall aspects
}

\author{
José Alberto de Souza FREITAS¹, Lucimara Teixeira das NEVES ${ }^{2}$, Ana Lúcia Pompéia Fraga de ALMEIDA ${ }^{3}$, Daniela \\ Gamba GARIB ${ }^{4}$, Ivy Kiemle TRINDADE-SUEDAM ${ }^{2}$, Renato Yassutaka Faria YAEDÚ ${ }^{5}$, Rita de Cássia Moura Carvalho \\ LAURIS $^{6}$, Simone SOARES ${ }^{3}$, Thais Marchini OLIVEIRA ${ }^{7}$, João Henrique Nogueira PINTO ${ }^{8}$
}

\begin{abstract}
1- DDS, MSc, PhD, Superintendent, Hospital for Rehabilitation of Craniofacial Anomalies (HRAC) and Full Professor, Department of Stomatology, Bauru School of Dentistry, University of São Paulo, Bauru, SP, Brazil.

2- DDS, MSc, PhD, Assistant Professor, Department of Biological Sciences, Bauru School of Dentistry and Hospital for Rehabilitation of Craniofacial Anomalies (HRAC), University of São Paulo, Bauru, SP, Brazil.

3- DDS, MSc, PhD, Assistant Professor, Departament of Prosthodontics, Bauru School of Dentistry and Hospital for Rehabilitation of Craniofacial Anomalies (HRAC), University of São Paulo, Bauru, SP, Brazil.

4- DDS, MSc, PhD, Associate Professor of Orthodontics, Department of Pediatric Dentistry, Orthodontics and Community Health, Bauru School of Dentistry and Hospital for Rehabilitation of Craniofacial Anomalies (HRAC), University of São Paulo, Bauru, SP, Brazil.

5- DDS, MSc, PhD, Assistant Professor, Department of Stomatology, Bauru School of Dentistry and Hospital for Rehabilitation of Craniofacial Anomalies (HRAC), University of São Paulo, Bauru, SP, Brazil.

6- DDS, MSc, Orthodontist of the Dental Division of the Hospital for Rehabilitation of Craniofacial Anomalies (HRAC), University of São Paulo, Bauru, SP, Brazil. 7- DDS, MSc, PhD, Assistant Professor, Department Pediatric Dentistry, Orthodontics and Community Health, Bauru School of Dentistry and Hospital for Rehabilitation of Craniofacial Anomalies (HRAC), University of São Paulo, Bauru, SP, Brazil.

8- DDS, MSc, PhD, Prosthodontist of the Dental Division of the Hospital for Rehabilitation of Craniofacial Anomalies (HRAC), University of São Paulo, Bauru, SP, Brazil.
\end{abstract}

Corresponding address: Lucimara Teixeira das Neves - Bauru School of Dentistry, University of São Paulo - Alameda Dr. Octávio Pinheiro Brisolla, 9-75 Bauru - SP - 17012-901 - Brazil - Phone: 551432358282 - Fax: 551432234679 - e-mail: lucimaraneves@usp.br

Received: September 13, 2011 - Accepted: October 8, 2011

\section{ABSTRACT}

left lip and palate is the most common among craniofacial malformations and causes
several esthetic and functional implications that require rehabilitation. This paper aims to
generally describe the several aspects related to this complex pathology and the treatment
protocol used by the Hospital for Rehabilitation of Craniofacial Anomalies, University of
São Paulo (HRAC-USP) along 40 years of experience in the treatment of individuals with
cleft lip and palate.

Key words: Cleft palate. Cleft lip.

\section{INTRODUCTION/HISTORY}

The initial motivation for this relevant work of rehabilitation for individuals with cleft lip and palate was initiated in the 1960s, encouraged by the scientific curiosity of a group of professors who conducted an epidemiological study on the occurrence of cleft lip and palate at the city of Bauru-SP, which revealed that one in each 650 children born presented a lip and palate congenital malformation ${ }^{13}$. In the early 1967 , stimulated by the result of this study, professionals from Bauru School of Dentistry began to provide assistance for these individuals by an integrated service of teaching, research and social care. Then, the Center for Research and Rehabilitation of Cleft Lip and Palate was established inside the School of Dentistry.

In 1976, "Centrinho" was transformed in an autonomous hospital unit under the name Hospital for Research and Rehabilitation of Cleft Lip and Palate - HPRLLP/USP, highlighted as "Center of Excellence in Care" by the University of São Paulo and as "world reference" by the World Health Organization. Therefore, in general, the Hospital is a consequence of this initial study and currently extended the treatment not only to individuals with cleft lip and palate, but also to subjects with hearing impairment. Because of these changes in its field 
of work, in 1998 "Centrinho" received a new name, which is valid so far: the Hospital for Rehabilitation of Craniofacial Anomalies, University of São Paulo (HRAC-USP).

Currently the Hospital, formed by a highly qualified multidisciplinary team, has more than 79,000 patients registered in all fields of treatment (cleft lip and palate, craniofacial malformations and hearing impairment), providing care to people from other places from Brazil and abroad. The institution differs from many others because of its interdisciplinary nature and the philosophy of humanized care and integral treatment.

During these more than 40 years of experience in the rehabilitation of people with cleft lip and palate, only in the year 2010 a total of 7,584 surgeries and 362,310 ambulatory attendances were offered, involving the several areas that compose the rehabilitation team. Only in the field of cleft lip and palate, 900 new cases are received per year in the average.

The field of teaching and research should also be emphasized, with post-graduation courses in specialization, Master and PhD degrees. Currently 95 research projects are being conducted, and only in the year 2010 the team of HRAC-USP published 45 papers.

\section{GENERAL ASPECTS OF CLEFT LIP AND PALATE}

\section{Embryology}

Cleft lip and palate is a relatively common craniofacial malformation that occurs between the $4^{\text {th }}$ and $12^{\text {th }}$ weeks of intrauterine life, period during which the embryonic development of the face and palate are taking place.

In general, the craniofacial development is a dynamic, complex and genetically controlled process. Histologically, it is initiated by proliferation and migration of neural crest cells originating from the midbrain. Migration of the second rhombomere, also called tail, in combination with these cells, presents anterior direction to form the first branchial arch, which gives rise to the face and its structures, in a mechanism determined by several molecular interactions ${ }^{19}$. Embryologically, there is proliferation of the lateral mesodermal layer reinforced by migration of neural crest cells. The facial structures are formed from mesodermization of the five facial prominences (one frontonasal, two maxillary and two mandibular prominences), with consequent elimination of grooves between them. Craniofacial malformations may occur when there is any deficiency or failure during these cell and molecular processes ${ }^{19}$.

The cleft lip and palate may present in two manners: as isolated deformities, or non-syndromic clefts, or within the phenotype of a syndrome, called syndromic clefts. In isolated cases it affects individuals without other physical or developmental anomalies $^{19}$. Several studies suggest that $60 \%$ to $70 \%$ of cases are isolated clefts, not associated to syndromes or malformations. The remaining 30\% to $40 \%$ of cases occur as a pattern of multiple malformations and are classified as a known syndrome related to chromosomal alterations, Mendelian disorder or exposure to a known teratogen. Currently there are more than 400 syndromes registered in the London Dysmorphology database which include clefts in their phenotypes².

The isolated or non-syndromic cleft lip and palate is the most common among the congenital malformations, affecting 1 in each 700 livebirths $^{2,15}$, even though there is variation in these data related to the geographic location and socioeconomic condition ${ }^{5,12,15,16}$. This prevalence is variable according to the ethnicity, being higher in individuals of Asian descent ( 1 in each 440 births), followed by Caucasoids ( 1 in each 650 births) and Blacks ( 1 in each 2 thousand births).

\section{Etiology}

Several factors are involved in the etiology of clefts; any physical, chemical or biological fact or agent acting on the differentiation, migration and proliferation of neural crest cells, with subsequent facial mesenchymal involvement, presents potential to determine the occurrence of cleft lip and palate. The etiopathogenic mechanism is related to a pattern of multifactorial inheritance, which requires the interaction between genetic and environmental factors, interfering with the molecular signalization and expression $6,15,16,18,19$. This association of factors impairs the identification of specific genes that determine this anomaly.

The discovery of genes responsible for syndromes involving cleft lip and palate in the clinical aspects (syndromic clefts) also allowed an understanding on the etiology of its most common type, the nonsyndromic cleft2,9,22. Studies on the recurrence pattern of non-syndromic clefts estimate that nearly 3 to 14 genes may be involved in the determination of this phenotype15,21. Linkage and association studies have indicated some candidate genes, including: TGFA, TGFB2, TGFB3, FGF, FOXE1, GLI2, JAG2, LHX8, SATB2, SKI, ERBB2, SPRY2, TBX10, MSX 2, MSX1 and IRF6 1,2,5,7,10,17-19,21. However, studies analyzing the sequencing of DNA samples of individuals with clefts indicated less influence of some candidate genes involved in the etiology of non-syndromic clefts, suggesting the possibility of genic interaction ${ }^{21}$. It is estimated that participation of the gene MSX1 in the occurrence of clefts is nearly $2 \%$; participation of the gene FGF, of $5 \%$; and $12 \%$ for the gene IRF615,21,24. However, new 
discoveries and confirmations on new candidate genes for this complex pathology arise every day.

The environmental factors most cited in the literature include smoking, alcohol and maternal characteristics as diseases and nutritional conditions, in addition to some drugs, analyzed in animal studies. These are some of the most analyzed environmental factors that may affect the embryogenesis and cause cleft lip and palate, when associated to a genetic predisposition ${ }^{2}$.

Despite some ambiguous results, the studies evidence that genetic and environmental factors play a role in the etiology of oral clefts, usually involving the gene-environment interaction in the determination of this phenotype ${ }^{2}$.

Some epidemiological studies have been conducted to test the gene-environment interaction, and the results of many such studies demonstrate this relationship for the occurrence of oral clefts. These studies analyzed some candidate genes and exposures to environmental factors that include modifying risk factors as smoking, alcohol intake and dietary factors as vitamin supplementation. Even though they found some modest association, relationships were found between TGFA and smoking and MSX1 and smoking 19,20.

Therefore, it is observed that non-syndromic cleft lip and palate in humans as a highly complex etiology, with participation of multiple genetic loci and exposure to several types of teratogens, influencing the individual susceptibility ${ }^{2}$.

Finally, the etiology of non-syndromic cleft lip and palate is still largely unknown, yet mutations in candidate genes have been identified in a small proportion of cases, determining the relative risk of cleft lip and palate based on the genetic background and environmental influence, including smoking during pregnancy, alcohol intake, and dietary factors ${ }^{3}$. All this knowledge aims at the genetic counseling and the development of future preventive measures ${ }^{2}$.

\section{TREATMENT PROTOCOL EMPLOYED AT THE HRAC-USP}

\section{Morphological variation/classification}

The orofacial clefts represent a heterogeneous group of disorders that affect the face and oral cavity, defining a complex phenotype that reflects a disorder in the normal mechanism involved during the early embryonic facial development. The morphological characteristics allow a better definition of this phenotypic diversity and the structures involved in the defect ${ }^{12}$.

Concerning the morphology, the cleft is clinically known by its large diversity, causing diverse anatomical impairments of variable severities, and to some extent to different treatment protocols.
Epidemiological studies demonstrate that cleft lip and palate, with or without palatal involvement, are more common among males, while isolated cleft palate is more common in females. Also, the type of cleft most frequently observed is unilateral cleft lip and palate and the left side is the most affected ${ }^{19}$.

As mentioned, the morphological variations in cleft lip and palate are extremely large, yet it is necessary to group them somehow, defining a standardization and providing a unification in the language between professionals involved in the treatment, allowing definition of the treatment protocol to be followed by the multi and interdisciplinary team according to the anatomical involvement caused by these morphological variations.

The HRAC follows the classification proposed in 1972 by Spina and colleagues, which considers the incisive foramen as anatomical point of reference, modified by Silva Filho, who suggested in 1992 a modification for the inclusion of median clefts $^{19}$. This classification with description of morphology allows definition of the diagnosis, rehabilitation and treatment prognosis of clefts according to the anatomical involvement, as well as its implications. According to these classifications, the clefts may also be divided in four large groups:

\section{Group I - Cleft lip}

This group involves the clefts affecting the lip with or without affecting the alveolar ridge and may be unilateral, bilateral or median. Concerning the extent, the defects range from a mild notch in the lip vermillion, called a cicatricial cleft, up to complete involvement of the lip and alveolar ridge, reaching the incisive foramen, when it is considered complete. Thus, inclusion or not of the entire extent of the alveolar ridge defines it as complete or incomplete. In cases classified as complete cleft lip, the cleft affects the lip and alveolar ridge reaching the incisive foramen. In cases classified as incomplete cleft lip, the cleft affects only the lip without involving the alveolar ridge (Figure 1).

\section{Group II - Complete cleft lip and palate}

According to the classification, this type of cleft completely involves the lip, alveolar ridge and palate, i.e. the cleft crosses the incisive foramen, and may be unilateral, bilateral or median (Figure $1)$.

\section{Group III - Cleft palate}

This group includes only cleft palate. This type of cleft involves the palate in different extents, totally or partially, also being described as complete or incomplete according to the extent of the cleft palate (Figure 1). 

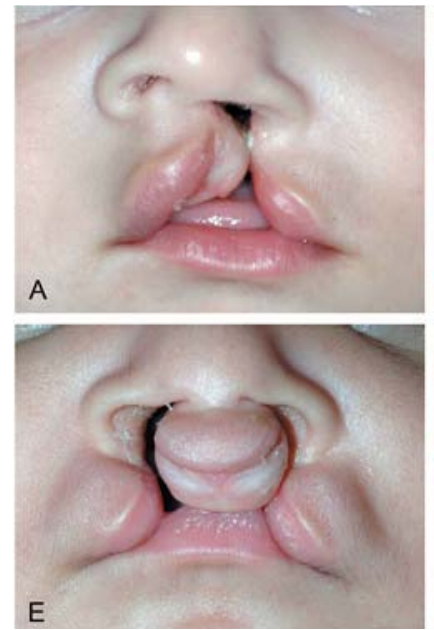
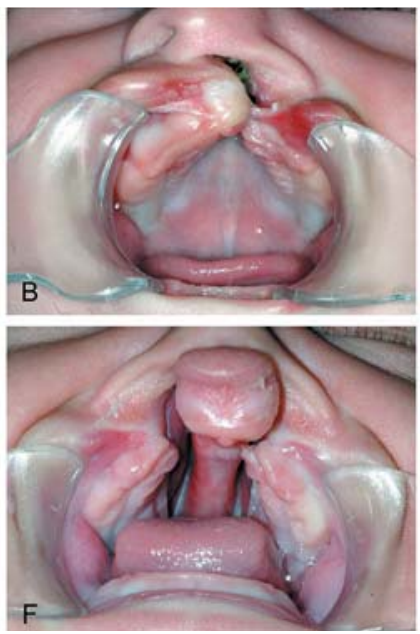
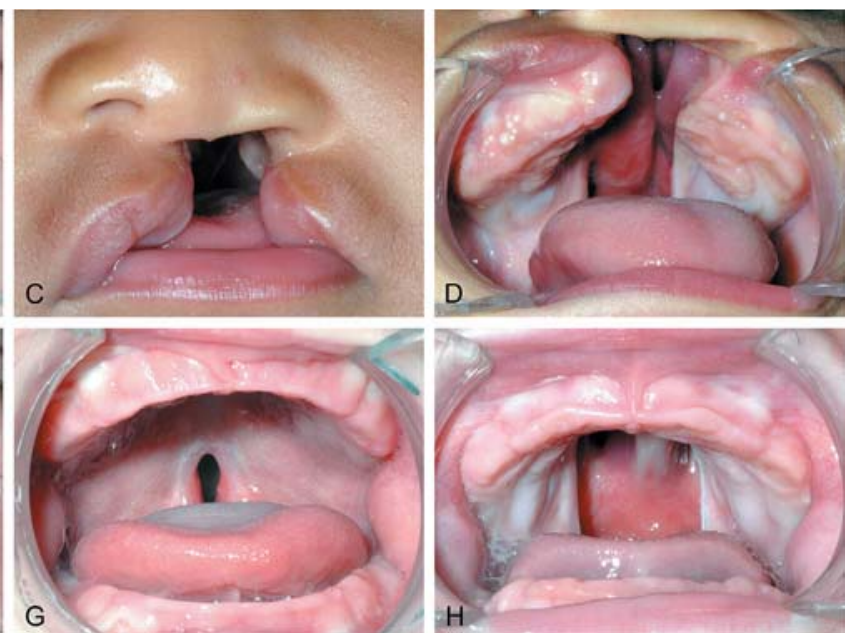

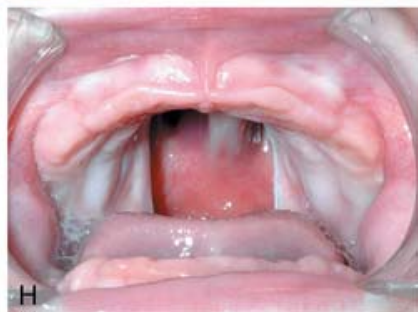

Figure 1- A and B - Complete unilateral cleft lip affecting the lip, alveolar ridge and anterior palate; C and D - Complete unilateral cleft lip and palate (affecting the lip, alveolar ridge and primary and secondary palate); E and F - Complete bilateral cleft lip and palate (affecting the lip, alveolar ridge and primary and secondary palate); G - Incomplete cleft palate (involving only the soft palate and uvula) and $\mathrm{H}$ - Complete cleft palate (completely involving the secondary palate)
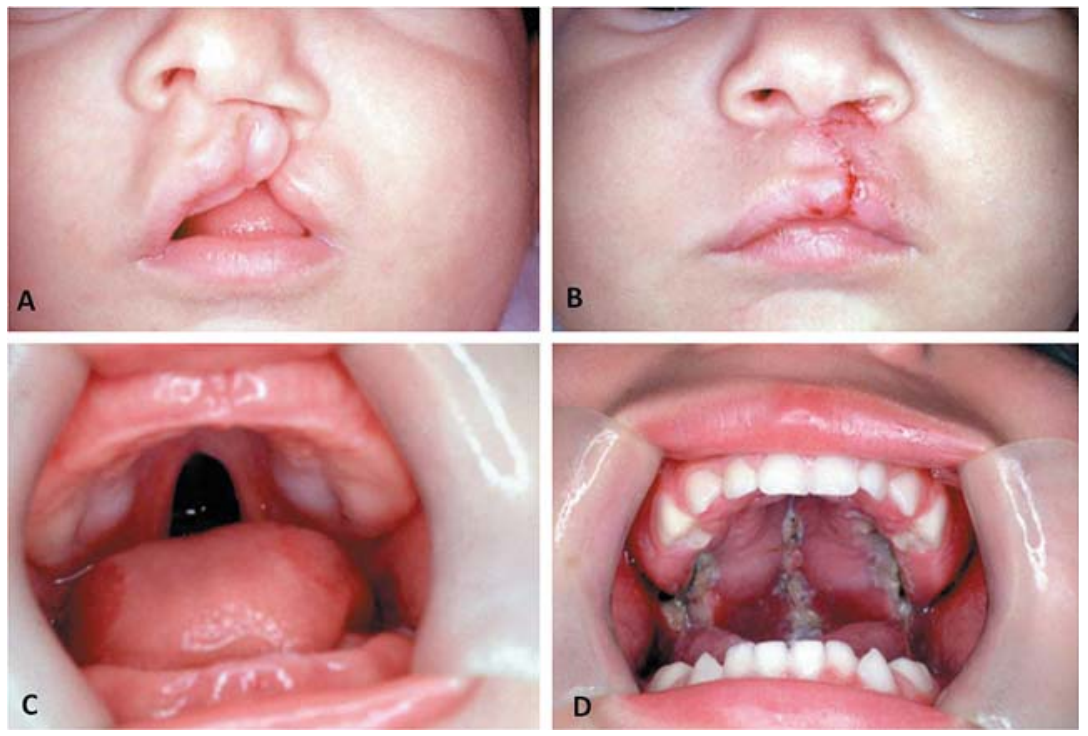

Figure 2-A and B - Pre- and postoperative aspect of cheiloplasty (surgical repair of the lip); C and D - Pre- and postoperative aspect of palatoplasty (surgical repair of the palate)

\section{Group IV - Rare facial clefts}

This group comprises the rare facial clefts, which not necessarily involve the incisive foramen, usually occurring distant from the areas of formation of the primary and secondary palate. They are also defined as atypical clefts because they involve other facial structures other than the lip and/or palate, such as the oro-ocular cleft, unilateral and/or bilateral macrostomia, cleft of the lower lip, mandibular cleft, palpebral cleft and oblique cleft, besides others.

In general, the severity of clefts depends on the severity of aggression to the normal embryonic development. The smaller interferences lead to occurrence of incomplete clefts, and the milder are called cicatricial cleft for the lip, affecting only the lip vermillion, and submucous cleft for the palate. All levels of severity are possible among complete and incomplete clefts, so as there are large variations in the quantity of tissue deficiency and consequently in the configuration of clefts ${ }^{2}$.

\section{Morphology and its consequences}

The problems caused by the cleft are complex, because the morphological alterations determine esthetic and functional impairments, which lead to others that also are relevant for the lives of people with malformations, namely the psychosocial implications ${ }^{4,11,12}$.

In cases of group I, which involve only the lip, the esthetics is the greatest impairment. When 
the alveolar ridge is completely or incompletely involved, in addition to the esthetic impairment there is also a dental disorder, since the continuity of the bone tissue in the alveolar ridge is disrupted by the presence of the defect. This influences the odontogenesis, because tooth buds are located at this region of the alveolar ridge, which then becomes susceptible to dental alterations.

In bilateral cases the prognosis is more critical, because the premaxilla is separated, and the esthetic involvement and growth are worsened. However, specifically in group I, the speech is not impaired because the palate is not affected.

Clefts in group II, namely complete unilateral cleft lip and palate, the maxilla is segmented in two different parts, with greater involvement of muscular tissue at the perilabial region, disrupting even the nasal base. This fragmentation causes the typical nasal asymmetry, with flattening and lowering of the alar cartilage at the cleft side and deviation of the nasal septum to the opposite side $^{14}$. All these characteristics initially affect the breastfeeding, and later predispose to dental and growth alterations, especially in sagittal direction ${ }^{4}$. Also, there are great implications for speech, because the palate is also segmented.

In cases of complete bilateral cleft lip and palate the morphological involvement is even greater, because the maxilla is segmented in three parts. There are two lateral segments and an anterior segment, called premaxilla, which presents variable size and anatomically is joined only to the anterior portion of the nasal septum. The marked projection of this structure is the main characteristic of bilateral clefts, causing the increased midface convexity. The prolabium is attached to the premaxilla, which usually presents little or no muscular tissue, besides deficient innervation and irrigation. The nose is characterized by a drastic reduction of the columella and lowering of the nasal apex. The premaxillary prognathism, also characteristic in the presence of complete bilateral cleft lip, is maintained with growth when not treated; however, it is reduced along the rehabilitative process by the primary surgery (cheiloplasty) performed in childhood. The facial transformation caused by progressive reduction of the midface convexity, which patients treated in conventional age present to greater or lesser extent, reveals the vulnerability of the premaxilla to plastic surgeries.

This type of cleft is the most invasive and presents the greatest impairment in all senses, both esthetic and functional, with difficulties in breastfeeding, alterations in maxillary growth, dental anomalies and speech impairment.

The complete bilateral cleft lip is the most severe among the classical types of cleft lip and palate and consequently presents greater esthetic and functional involvement, requiring greater number of surgical interventions and outpatient procedures during the rehabilitative process.

Clefts in group III that morphologically involve only the palate, either completely or incompletely, cause greater functional implications in early ages for breastfeeding, because of the difficulty to establish adequate negative intraoral pressure that is necessary for milk suction during feeding. At later ages there is significant speech impairment, especially related to the velopharyngeal mechanism, which causes the characteristic nasal speech ${ }^{23}$. Also, in many cases the hearing is affected because of the communication between the oral and nasal cavities during a period of life, which predisposes to recurrent otitis and greater risk of hearing loss ${ }^{8}$. The esthetics is not affected because the facial structures and characteristics are normal.

The rare facial clefts present different morphological characteristics, since they involve several different types of structures, often impairing the oral cavity, nose and orbit, besides other structures. Obviously, the greater the number of structures involved, the greater will be the anatomical impairment and esthetic and functional characteristics.

\section{General treatment protocol}

The first consultation to HRAC-USP is called new case consultation. At this moment, a team currently composed of a plastic surgeon, a dental professional and a speech therapist perform an initial evaluation to diagnose the type of cleft, registering the patient in the Hospital. In the same consultation with this group of professionals the parents are informed on the therapeutic approach to be followed and receive initial counseling in several areas. These complementary attendances aim to guide the parents on the several impairments caused by the cleft and how they should manage each of them.

According to the types of cleft, the team of HRACUSP established protocols which generally define the treatment pattern to be followed, obviously respecting the expectations of the patients and their families, as well as the individual peculiarities and needs of each case. These therapeutic approaches were established by the analysis of outcomes during the several stages of rehabilitation and are based on the experience of HRAC-USP during these 40 years in the treatment of craniofacial anomalies.

Since the rare clefts are uncommon, they do not present well-defined treatment protocols as those established for classical cleft lip and palate (groups I, II and III), since each of them may involve different anatomical structures. Therefore, the therapeutic approach is defined by the team analyzing each case and his or her needs individually.

The first surgical step of the therapeutic 
approach comprises the surgeries for cleft repair, and there is great expectation of the parents at this stage. In general, for classical types of clefts, the timing followed by HRAC-USP for lip and palate repair are as follows: cheiloplasty, which is the surgical lip repair, is ideally performed at three months of age; and palatoplasty, the surgical reconstruction of the palate, is performed at the age of 12 months (Figure 2). To follow this timing, the health status of the child is previously evaluated to perform the procedure. At the period between these two surgeries the patient has outpatient follow-up consultations in the fields of pediatrics and pediatric dentistry, besides others in continued follow-up.

In cases of clefts affecting the palate, around 12 months during the pre- and postoperative period of palatoplasty up to three years of age the patient must be evaluated by the speech therapist concerning the need of intervention for speech therapy, as well as audiometric evaluations.

Around 6 years of age, patients with any type of cleft should be reevaluated specifically regarding the surgical outcome of primary surgeries, analyzing the need and opportunity to perform a second surgical stage that comprises secondary surgeries. In cases of patients with clefts involving the lip a secondary cheiloplasty may be necessary for esthetic correction of the lip, and cases with cleft palate may require pharyngoplasty with the main objective of speech enhancement, or even correction of fistulas that may occasionally appear after palatoplasty and that might also impair the speech.

In the dental clinic, the patient is evaluated at the preventive orthodontics clinic for analysis of craniofacial development and prognosis and treatment plan to be followed for each case.

Subsequently, the patient is intensely and more frequently followed by the different dental specialties, which are responsible for a major part of esthetic rehabilitation with the main objective of intervention for treatment of maxillomandibular discrepancies and therapeutic approaches for rehabilitation of dental anomalies and other highly prevalent oral pathologies in individuals with cleft lip and palate.

\section{FINAL CONSIDERATIONS}

In general, the treatment of craniofacial anomalies depends on a highly specialized rehabilitation and is initiated early, involving several medical, dental and related specialties.

When not treated, cleft lip and palate may have an impact on several important areas for the integration in society. Thus, the rehabilitation aims not only to allow this integration for individuals, but to provide their full social inclusion ${ }^{11,19}$.
In general, the rehabilitation process comprises these healthcare actions described in this paper for the assistance to people with cleft lip and palate. All this process involves the action of a multidisciplinary team in a relationship of reciprocity, mutuality and dialogue. The collaboration between different areas is fundamental in this relationship ${ }^{19}$.

\section{REFERENCES}

1- Blanton SH, Cortez A, Stal S, Mulliken JB, Finnell RH, Hecht JT. Variation in IRF6 contributes to nonsyndromic cleft lip and palate. Am J Med Genet. 2005;137A:259-62.

2- Dixon MJ, Marazita ML, Beaty TH, Murray JC. Cleft lip and palate: understanding genetic and environmental influences. Nat Rev Genet. 2011;12:167-78.

3- Etheredge AJ, Christensen K, Del Junco D, Murray JC, Mitchell LE. Evaluation of two methods for assessing gene-environment interactions using data from the Danish case-control study of facial clefts. Birth Defects Res A Clin Mol Teratol. 2005;73:541-6. 4- Jezewski PA, Vieira AR, Nishimura $C$, Ludwig $B$, Johnson $M$, O'Brien SE, et al. Complete sequencing shows a role for MSX1 in non-syndromic cleft lip and palate. J Med Genet. 2003;40:399407.

5- Jia Z, Li Y, Li L, Wu J, Zhu LY, Yang C, et al. Association among IRF6 polymorphism, environmental factors, and nonsyndromic orofacial clefts in Western China. DNA Cell Biol. 2009;28:249-57. 6- Jugessur A, Shi M, Gjessing HK, Lie RT, Wilcox AJ, Weinberg $\mathrm{CR}$, et al. Genetic determinants of facial clefting: analysis of 357 candidate genes using two national cleft studies from Scandinavia. PLoS One. 2009;4:e5385.

7- Kondo S, Schutte BC, Richardson RJ, Bjork BC, Knight AS, Watanabe $Y$, et al. Mutations in IRF6 cause Van der Woude and popliteal pterygium syndromes. Nat Genet. 2002;32:285-9.

8- Kwan WM, Abdullah VJ, Liu K, van Hasselt CA, Tong MC. Otitis media with effusion and hearing loss in Chinese children with cleft lip and palate. Cleft Palate Craniofac J. 2011;48:684-9.

9- Marazita ML, Lidral AC, Murray JC, Field LL, Maher BS, Goldstein McHenry T. Genome scan, fine-mapping, and candidate gene analysis of non-syndromic cleft lip with or without cleft palate reveals phenotype-specific differences in linkage and association results. Hum Hered. 2009;68:151-70.

10- Millar K, Bell A, Bowman A, Brown D, Lo TW, Siebert P, et al. Psychological status as a function of residual scarring and facial asymmetry after surgical repair of cleft lip and palate. Cleft Palate Craniofac J. 2011 Aug 16. [Epub ahead of print].

11- Mossey PA, Little J, Munger RG, Dixon MJ, Shaw WC. Cleft lip and palate. Lancet. 2009;374:1773-85.

12- Murray JC. Face facts: genes, environment and clefts. Am J Hum Genet. 1995;57:227-32.

13- Nakatsuka K, Adachi T, Kato T, Murakami M, Yamada M, Masuda Y. Asymmetric lip-closing forces in children with repaired unilateral cleft lip and/or palate. J Oral Rehab. 2011;38:921-8.

14- Riley BM, Mansilla MA, Ma J, Daack-Hirsch S, Maher BS, Raffensperger LM, et al. Impaired FGF signaling contributes to cleft lip and palate. Proc Natl Acad Sci U S A. 2007;104:4512-7. 15- Shaw GM, Wasserman CR, Lammer EJ, O'Malley CD, Murray GC, Basart AM, et al. Orofacial clefts, parental cigarette smoking, and transforming growth factor-alpha gene variants. Am J Hum Genet. 1996;58:551-61.

16- Slayton RL, Williams L, Murray JC, Wheeler JJ, Lidral AC, Nishimura CJ. Genetic association studies of cleft lip and/or palate with hypodontia outside the cleft region. Cleft Palate Craniofac J. 2003;40:274-9.

17- Sull JW, Liang KY, Hetmanski JB, Fallin MD, Ingersoll RG, Park J, et al. Maternal transmission effects of the PAX genes among cleft case-parent trios from four populations. Eur J Hum Genet. 2009;17:831-9. 
18- Tang W, Du X, Feng F, Long J, Lin Y, Li P, et al. Association analysis between the IRF6 G820A polymorphism and nonsyndromic cleft lip and/or palate in a Chinese population. Cleft Palate Craniofacial J. 2009;46:89-92.

19- Trindade IEK, Silva Filho OG. Fissuras labiopalatinas - uma abordagem interdisciplinar. São Paulo: Ed. Santos; 2007.

20- Van den Boogaard MJ, Costa D, Krapels IP, Liu F, van Duijn C, Sinke RJ, et al. The MSX1 allele 4 homozygous child exposed to smoking at periconception is most sensitive in developing nonsyndromic orofacial clefts. Hum Genet. 2008;124:525-34.

21- Vieira AR. Unraveling human cleft lip and palate research. J Dent Res. 2008;87:119-25.
22- Vieira AR, Cooper ME, Marazita ML, Orioli IM, Castilla EE. Interferon Regulatory Factor 6 (IRF6) is associated with oral-facial cleft in individuals that originate in South America. Am J Med Genet A. 2007;143A:2075-8.

23- Ysunza A, Carmen Pamplona M, Santiago Morales MA. Velopharyngeal valving during speech, in patients with velocardiofacial syndrome and patients with non-syndromic palatal clefts after surgical and speech pathology management. Int J Pediatr Otorhinolaryngol. 2011;75:1255-9.

24- Zucchero TM, Cooper ME, Maher BS, Daack-Hirsch S, Nepomuceno B, Ribeiro L, et al. Interferon regulatory factor 6 (IRF6) gene variants and the risk of isolated cleft lip or palate. New Engl J Med. 2004;351:769-80. 